\title{
A RARE SURGERY: MYOMECTOMY ON PREGNANT UTERUS
}

\section{U. Agnes Vijaya1, Anusha Patel2 ${ }^{2}$ Purushothama Reddy K}

\section{HOW TO CITE THIS ARTICLE:}

U. Agnes Vijaya, Anusha Patel, Purushothama Reddy K. "A Rare Surgery: Myomectomy on Pregnant Uterus". Journal of Evolution of Medical and Dental Sciences 2015; Vol. 4, Issue 72, September 07; Page: 12605-12609, DOI: $10.14260 /$ jemds/2015/1815

ABSTRACT: BACKGROUND: Leiomyomas also called myomas or fibroids; are benign monoclonal uterine myometrial tumors. Uterine fibroids are the commonest benign tumours of female genital tract with a prevalence of 20 to $50 \%$ in women of reproductive age. Fibroids may be classified as submucous, intramural or sub-serous. It is often assumed that fibroids cause infertility since pregnancies do occur after myomectomy and other treatments where the fibroids are removed. The treatment of fibroids has historically been surgery, usually hysterectomy. Myomectomy is an option in women wishing to maintain fertility and for those desiring to keep their uterus. The position of the uterine fibroid plays important role in infertility. The presence of sub-mucous fibroid decreases the fertility rate. Subserosal fibroids do not affect the fertility rate but removing those does increase fertility. Surgical management is limited to non-pregnant uterus. Fibroid coexisting pregnancy, prevalence is $0.3-2.6 \%$, can be associated with complication in 10 to $30 \%$ cases which are managed conservatively. We present a case of multiple fibroid complicating pregnancy with one huge sub-serosal pedunculated fibroid extending up to xiphisternum that necessitated myomectomy at 18 to 20 weeks of gestation.

KEYWORDS: Pregnancy, Fibroid, Discomfort, Myomectomy \& Growing fetus.

INTRODUCTION: Uterine fibroids are commonest benign tumours of female genital tract with a prevalence of 20 to $50 \%$ in women of reproductive age. Surgical management is limited to nonpregnant uterus. Fibroid coexisting pregnancy, prevalence is $0.3-2.6 \%$, can be associated with complications in 10 to $30 \%$ cases which are managed conservatively. ${ }^{1}$ The most common complication is the syndrome of 'painful myoma' i.e., due to red or carneous degeneration and occurs in $\sim 5-8 \%$ of myomas during pregnancy. This complication is associated with nausea, vomiting and fever, and usually occurs during the $2^{\text {nd }}$ trimester of pregnancy. ${ }^{2}$

The aim of the present study was to evaluate the safety and efficacy of myomectomy during the $2^{\text {nd }}$ trimester of pregnancy.

Complications include pregnancy loss, pelvic pain, placental abruption, hydronephrosis and premature rupture of membranes, preterm labor, intrauterine growth restriction, fetal malpresentation and postpartum hemorrhage. The prevalence of these complications is increased if there are multiple masses, if a myoma is intramural and retro placental and if a myoma is larger than $3.6 \mathrm{~cm}$ in diameter $\left(200 \mathrm{~cm}^{3}\right) .^{3}$ Conservative management is the first line of treatment during pregnancy and consists of bed rest, hydration and analgesics. If these measures fail, patients may be presented the option of induced abortion with myomectomy at a later date.

The literature consists mainly of case reports and retrospective studies; there are few prospective studies of pregnancy-preserving myomectomies. ${ }^{4}$ Majority of these surgeries were performed in the $2^{\text {nd }}$ trimester for intractable pelvic pain and had excellent outcomes, very few pregnancy losses and no hysterectomies have been reported. Traditional recommendations, including operating only on pedunculated myomas, only during the $4^{\text {th }} \& 6^{\text {th }}$ month of pregnancy or only during the $14^{\text {th }}$ to $15^{\text {th }}$ week of gestation, warrant re-evaluation. ${ }^{5}$ 
Literature documenting $1^{\text {st }}$ trimester surgical management of myomas during pregnancy is scant. Patients with symptomatic myomas failing conservative management in the 1 st trimester may be counseled to abort the pregnancy and then undergo myomectomy. Reports focusing on myomectomy in the $1^{\text {st }}$ trimester are needed to permit more thorough options for counseling of patients failing conservative management in the $1^{\text {st }}$ trimester. ${ }^{6}$

Because of the increased vascularization of the uterus during pregnancy, women are at increased risk of bleeding and postoperative morbidity after myomectomy. Some reports have shown that myomectomy during cesarean delivery can be safe. Controversy persists among reports of myomectomy being performed during pregnancy, with some case series having reported the safety of antepartum myomectomy in carefully selected patients.

\section{The Criteria for Deciding to Submit to Myomectomy during Pregnancy were: ${ }^{7}$}

(i) Rapidly growing leiomyoma causing discomfort.

(ii) Severe abdominal pain (Painful myoma) that did not respond to conservative management,

(iii) A distance between the leiomyoma and the endometrial cavity $>5 \mathrm{~mm}$, in order to avoid opening of the endometrial cavity; and

(iv) The provision of a signed consent form, after the patients had been informed of the risks of surgical intervention.

We present a case of multiple fibroid complicating pregnancy with 1 huge sub-serosal pedunculated fibroid extending upto xiphisternum that necessitated myomectomy at 18 to 20 weeks gestation.

CASE REPORT: A 32 years old elderly Primigravida referred to our hospital with a history of 4 months gestation and distension of abdomen along with pain in abdomen from 1 week. On further examination, her abdomen distended up-to xiphisternum. The distension was solid and firm in consistency. By ultrasound, diagnosis of a huge sub-serosal fundal fibroid with multiple fibroid uterus with single live intra uterine live foetus of 16 week gestation was made. After thorough investigations, correction of haemoglobin $(\mathrm{Hb})$ was done. Due to acute abdominal distress, at 18 to 20 weeks gestation emergency laparotomy was performed by Right Para-median incision. A huge subserosal pedunculated fibroid about $5 \mathrm{~kg}$ from the fundal region removed. Foetal monitoring was carried out intra and post operatively to assess the viability. Her post-operative period was uneventful. Subsequent Antenatal period was uncomplicated. Anaemia was corrected. She delivered a live Mch, $3 \mathrm{~kg}$ at 37 completed weeks of gestation by elective LSCS. During caesarean section of 4 sessile myomas were also enucleated. One intramural anterior wall on the Right side could not be operated. Her post-operative period was uneventful. Both mother and baby are healthy.

DISCUSSION: The decision to remove the fibroid was justified by its size and the patient's symptoms. The benefit was the relief of symptoms and facilitating the space to accommodate growing fetus and enlarging gravid uterus. A tissue diagnosis of a very large, suspicious abdominal mass made by histopathological examination to exclude malignancy. Its pedunculated sub-serosal location may have contributed to easy removal. Hypercoagulability in pregnancy might have contributed to the ease in achieving hemostasis. ${ }^{8}$ 
The ease with which the fibroid was removed and the minimal measures used to obtain hemostasis contributed to the safety of the procedure. ${ }^{9}$ This case illustrates that myomectomy during pregnancy can be safely performed in carefully selected cases. Pregnant women with myoma should undergo frequent ultrasound evaluation during pregnancy in order to monitor both fetal growth and myoma size. Of note, when serial ultrasonography was used to monitor leiomyomas during pregnancy, only half of the lesions examined showed a significant change in size.

During the $1^{\text {st }}$ trimester, leiomyomas of all sizes either remained unchanged or increased in size, whereas during the $2^{\text {nd }}$ trimester smaller myomas $(2-6 \mathrm{~cm})$ usually remained unchanged or increased in size whilst larger myomas became smaller. During the $3^{\text {rd }}$ trimester, myomas usually remained unchanged or decreased in size, regardless of their initial dimensions. ${ }^{10}$ It was noted that, as both size and number of myomas increased, a significantly higher frequency of retained placentas, fetal malpresentations and preterm contractions was identified.

Red or carneous degeneration may present with localized pain and tenderness, fever and an elevated white blood cell count. In most cases of red degeneration, ultrasound findings reveal cystic spaces in the myomas. ${ }^{11}$ Although medical therapy - including analgesics, fluids and antibiotics may be used in the majority of these patients. In patients with severe abdominal pain or an increase in myoma size causing abdominal pain and discomfort, a timely and well-planned myomectomy should be an option. ${ }^{12}$

CONCLUSION: Though conservative management of myoma in the gravid state is gold standard. Myomectomy during pregnancy is often advantageous when performed early and judiciously on selected patients especially in case of Subserosal pedunculated fibroid.

In conclusion, the present data provide reassurance for pregnant women with uterine myoma. The surgical management of uterine leiomyoma during pregnancy may be performed successfully in carefully selected patients and this seems to lead to an improvement in pregnancy outcome.

We believe that our experience provides reassurance for pregnant women with uterine myomas, the surgical management of uterine myomas during pregnancy can be successfully performed by expert surgeons on a case-by-case basis. Myomectomy during pregnancy should be performed only if unavoidable. In selected patients it could prevent miscarriage or an unacceptable obstetrical outcome.

The surgical approach should be tailored to the patient and to the characteristics of the myoma. Clearly, an expert surgical and anesthesiological team is essential in order to reduce risk of complications. Indications for myomectomy during pregnancy include severe abdominal pain due to torsion of sub-serous pedunculated myomas or red degeneration not responding to medical treatment and an increase in myoma size causing abdominal discomfort. It has been reported that if symptoms persist after 72 hours of therapy, then surgical intervention must be considered.

CLINICAL RELEVANCE: The sub-serosal pedunculated large fibroid, causing distress enabled us to proceed for Myomectomy. 


\section{CASE REPORT}

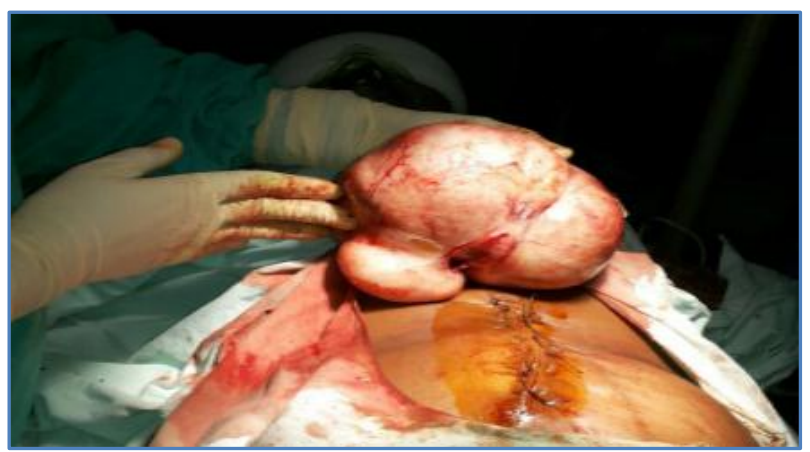

Pic. 1: Huge Subserosal fibroid about $5 \mathrm{~kg}$ with 20 weeks of gravid uterus

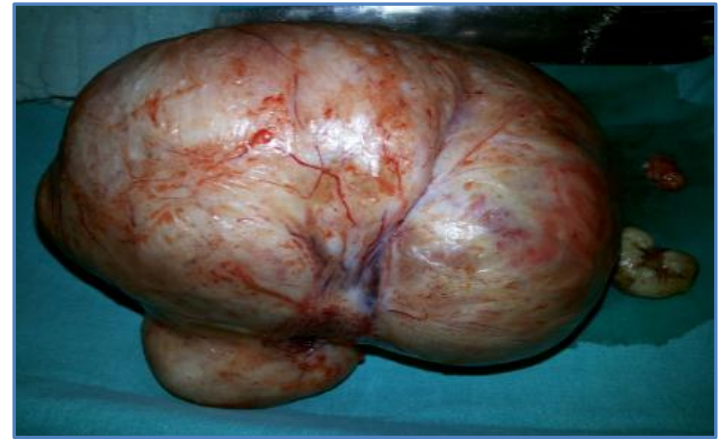

Pic. 2: Post-operative picture of Myoma ( $5 \mathrm{~kg}$ )

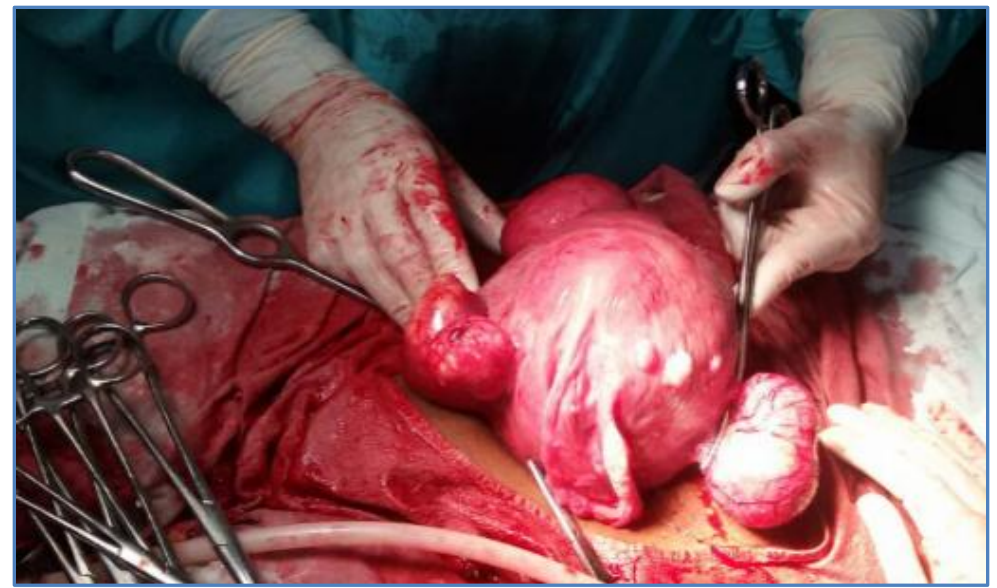

Pic. 3: After Caesarean section other Sessile Subserosal fibroids4 and 1 intra mural fibroid at corneal end which could not be removed

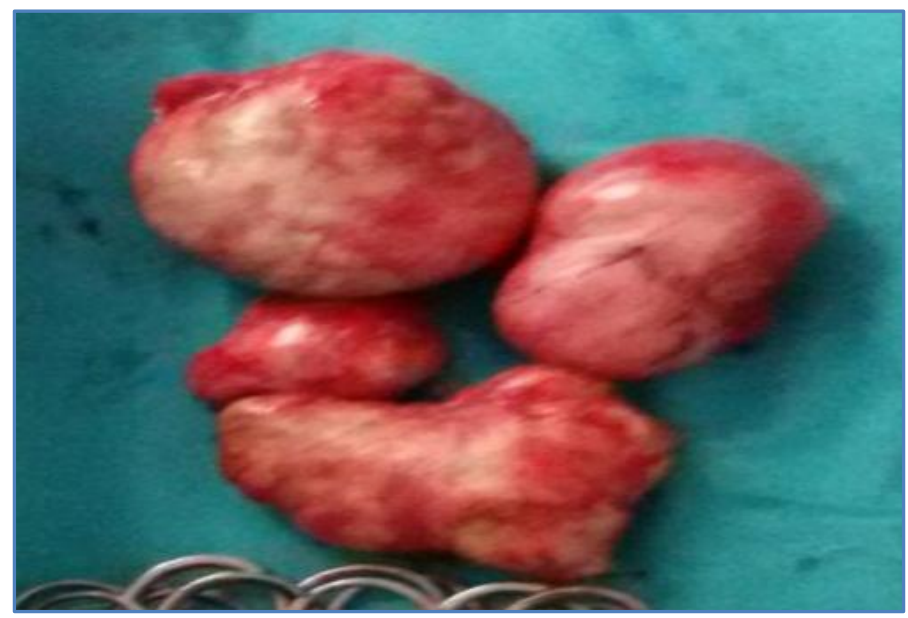

Pic. 4: Picture of removed sessile Subserosal Myomas (4) 


\section{BIBLIOGRAPHY:}

1. Seinera P, Arisio R, Decko A, et al: Laparoscopic myomectomy: Indications, surgical technique and complications. Hum Reprod 12: 1927-1930, 1997.

2. Acien P, Quereda F: Abdominal myomectomy: Results of a simple operative technique. Fertil Steril 65:41-51, 1996.

3. Nezhat $\mathrm{CH}$, Nezhat F, Roemisch M, et al: Pregnancy following laparoscopic myomectomy: Preliminary results. Hum Reprod 14(5): 1219-1221, 1999.

4. Burton CA, Grimes DA, March CM: Surgical management of leiomyomata during pregnancy. Obstet Gynecol 1989, 74: 707.

5. Exacoustos C, Rosati P: Ultrasound diagnosis of uterine myomas and complications in pregnancy. Obstet Gynecol 1993, 82: 97-101.

6. Michalas SP, Oreopoulou FV, Papageorgiou JS: Myomectomy during pregnancy and caesarean section. Human Reproduction 1995, 10: 1869-70.

7. Lolis DF, Kalantaridou SN, Makrydimas G, Sotiriadis A, Navrozoglu I, Zikopoulos K, Paraskevaidis EA: Successful myomectomy during pregnancy. Human Reproduction 2003, 18: 1699-1702.

8. Douth waite A. H. et al., Pregnancy and its complications laparoscopic myomectomy, American journal of Obstet. \& Gynecol., 1936, volume 2: page no.: 531 - 538.

9. Minot G. R., Strauss M. B. and Cobb S., Laparoscopic myomectomy- a ideal procreative potential for pregnancy outcome, New England Journal of Medicine, 1933, volume 16: page no.: 12331244.

10. Strauss M. B. et al., Myomectomy for fibroid uterus a case report, American Journal of medical \& Sciences, 1935, volume 14: Page no.: 189-199.

11. Seracchioli R, Rossi S, Govoni F, et al. Fertility and obstetric outcome after laparoscopic myomectomy of large myomata: a randomized comparison with abdominal myomectomy. Hum Reprod. 2000; 15(12):2663-2668.

12. Levy BS. Modern management of uterine fibroids. Acta Obstet Gynecol Scand. 2008; 87(8): 812-823.

\section{AUTHORS: \\ 1. U. Agnes Vijaya \\ 2. Anusha Patel \\ 3. Purushothama Reddy K.}

\section{PARTICULARS OF CONTRIBUTORS:}

1. Associate professor, Department of Obstetrics \& Gynaecology, RIMS, Kadapa.

2. Post Graduate, Department of Obstetrics \& Gynaecology, RIMS, Kadapa.

3. Associate professor, Department of Pharmacy Practice, PRRMCP, Kadapa.
NAME ADDRESS EMAIL ID OF THE CORRESPONDING AUTHOR:

Purushothama Reddy K, Associate Professor, Department of Pharmacy Practice, P. Rami Reddy Memorial College of Pharmacy, Kadapa-516003, Andhra Pradesh.

E-mail: reddypharma6@gmail.com

Date of Submission: 22/08/2015.

Date of Peer Review: 24/08/2015.

Date of Acceptance: 02/09/2015.

Date of Publishing: 07/09/2015. 